\section{Predizendo Riscos para Tivoidite Pós-Parto Através da Dosagem de Anticorpo Anti-TPO: Exemplo de Valor da Pesquisa Clínica}

$\mathrm{E}$ mbora as primeiras descrições de hipotiroidismo transitório em mulheres no período de puerpério datem de 1948, durante várias décadas esta condição despertou pouca atenção da literatura (1-3). Relatos de novos casos foram sendo feitos com freqüência cada vez maior e logo começaram a aparecer diversos estudos epidemiológicos e fisiopatológicos caracterizando-se, finalmente, a tiroidite pós-parto (TPP) como entidade clínico-nosológica (4).

Inicialmente, a doença foi considerada como uma forma de tiroidite sub-aguda sem dor (5). Atualmente, com a demonstração de associação com antígenos DR e antígenos anti-tiroidianos, pela presença de infiltração linfocitária na tiróide, com diminuição da razão linfócitos $\mathrm{T}$ helper / $\mathrm{T}$ supressores durante a gravidez e no pós-parto, associada com grande ativação das células $\mathrm{T}$ no puerpério, a doença é considerada como uma patologia autoimune transitória relacionada à hiperatividade imunológica do puerpério $(4,6-8)$.

Também tem ficado patente que se trata de condição relativamente comum. Estima-se que atinja $4,9 \%$ das mulheres no primeiro ano pósparto, variando sua prevalência na literatura entre $4,2 \%$ e $19,7 \%$ (6).

Neste número dos Arquivos Brasileiros de Endocrinologia e Metabologia, Barros e Vaisman (9) encontraram uma prevalência similar, diagnosticando quatro portadoras de TPP dentre 115 pacientes. Demonstraram ainda uma associação entre a presença de anticorpos antitiroidianos durante a gravidez e no período pós-parto, com o desenvolvimento de TPP e de hipotiroidismo sub-clínico. Existem, também, evidências de correlação entre anticorpos anti-TPO e outros anticorpos antitiroidianos com o desenvolvimento da doença de Basedow-Graves puerperal (10). Mais ainda, um quarto das mulheres com TPP desenvolvem hipotiroidismo permanente num período de quatro anos após o parto (11). Desta forma, a TPP é um indicador de futuras disfunções tiroidianas, embora não esteja ainda claro se a gravidez inicia um processo destrutivo da glândula ou simplesmente exacerba uma lesão pré-existente. Assim, apresenta-se uma interessante oportunidade para a prevenção de disfunções que, além de freqüentes, podem ser de grande morbidade, causando inúmeros transtornos à mulher e ao seu filho, particularmente quando se associam à depressão pós-parto.

Um grande mérito do artigo de Barros e Vaisman (9), reside em demonstrar como podem ser obtidos dados científicos de valor e de aplicação prática imediata, de forma simples e com custos relativamente pequenos. A pesquisa clínica tem sido relegada a um segundo plano, desmotivada e desvalorizada, particularmente nos grandes centros universitários. Ora, em nosso país mal conhecemos muitas de nossas doenças mais prevalentes. No caso das tiroidopatias, isto se torna crucial quando lembramos que ainda possuímos grandes bolsões de áreas iodoprivas. Se somarmos a esta informação as alarmantes incertezas sobre o programa de correção da carência crônica de iodo no país, é de se imaginar que possuí- editorial

\author{
Laura Sterian Ward
}


mos um perfil de doenças tiroidianas diferente do relatado nos países onde este tipo de situação já não existe há decadas (12). Doenças provavelmente com prevalência, quadro clínico e evolução diferentes.

Sem ofuscar o inegável brilho de vários pesquisadores nacionais que, com todo sacrificio imposto pelo sistema, têm conseguido trazer importantes contribuições ao mundo científico, creio que devemos louvar e incentivar trabalhos como o de Barros e Vaisman, que nos trazem suporte para apregoarmos uma conduta prática imediata, simples e eficaz: procurar anticorpos anti-tiroidianos em grávidas de risco para desenvolver TPP, principalmente naquelas diabéticas.

\section{REFERÊNCIAS}

1. Roberton HEW. Lassitude, coldness, and hair changes following pregnancy, and their response to treatment with thyroid extract. Brit Med J 1948;2(suppl):2275-6.

2. Amino N, Miyai K, Onishi T, et al. Transient hypothyroidism after delivery in autoimmune thyroiditis. J Clin Endocrinol Metab 1976;42:296-301.

3. Ginsberg J. Walfish PG. Postpartum transient thyrotoxicosis with painless thyroiditis. Lancet 1977;1:11125-7.
4. Mizukami $Y$, Michigishi T, Nomura A, et al. Postpartum thyroiditis. A clinical, histologic, and immunopathologic study of 15 cases. Am J Clin Pathol 1993;100:200-5.

5. Volpe R. The pathology of thyroiditis. Hum Pathol 1978;9:429-38.

6. Gerstein HC. How common is postpartum thyroiditis? A methodologic overview of the literature. Arch intern Med 1990; 150: 1397-400.

7. LiVolsi VA. Postpartum thyroiditis. The pathology slowly unravels (editorial). Am J Clin Path 1993;100:193-5.

8. Dayan CM, Gilbert HD. Chronic autoimmune thyroiditis. N Eng J Med 1996;335:99-107.

9. Barros AFP, Vaisman M. Tiroidite pós-parto: Prevalência e evolução clínica. Arq Bras Endocrinol Melab 1998; 42/6:451-455.

10. Hidaka Y, Tamaki H, Iwatani Y, Tada H, Mitsuda N, Amino $N$. Prediction of post-partum Graves thyrotoxicosis by measurement of thyroid stimulating antibody in early pregnancy. Clin Endocrinol 1994;41:15-20.

11. Othman S, Phillips DI, Parkes AB, Richards CJ, Harris B. Fung $\mathrm{H}$, et al. A long-term follow-up of post-partum thyroiditis. Clin Endocrinol 1990;32:559-64.

12. Medeiros-Neto $G$. Programa de correção da carência crônica de iodo no Brasil através da adição de iodo ao sal: do sucesso inicial à incerteza atual. Arq Bras Endocrinol Metab 1998;42:235-7. 